\title{
Impact of tofacitinib on patient outcomes in rheumatoid arthritis - review of clinical studies
}

This article was published in the following Dove Press journal:

Patient Related Outcome Measures

14 January 2016

Number of times this article has been viewed

\section{Eric G Boyce \\ Deepti Vyas \\ Edward L Rogan \\ Cynthia S Valle-Oseguera \\ Kate M O'Dell}

Department of Pharmacy Practice, Thomas J Long School of Pharmacy and Health Sciences, University of the Pacific, Stockton, CA, USA
Correspondence: Eric G Boyce

Department of Pharmacy Practice,

Thomas J Long School of Pharmacy and Health Sciences, University of the Pacific, 360I Pacific Avenue, Stockton, CA

9521I, USA

Email eboyce@pacific.edu
Abstract: Rheumatoid arthritis is a chronic, progressive autoimmune disease associated with inflammation and destruction of joints and systemic effects, which result in significant impact on patient's quality of life and function. Tofacitinib was approved for the treatment of rheumatoid arthritis in the USA in 2012 and subsequently in other countries, but not by the European Medicines Agency. The goal of this review was to evaluate the impact of tofacitinib on patientreported and patient-specific outcomes from prior clinical studies, focusing on quality of life, functionality, pain, global disease assessment, major adverse consequences, and withdrawals. A total of 13 reports representing 11 clinical studies on tofacitinib in rheumatoid arthritis were identified through PubMed and reference lists in meta-analyses and other reviews. Data on improvements in patient-driven composite tools to measure disease activity in rheumatoid arthritis, such as the Health Assessment Questionnaire, served as a major outcome evaluated in this review and were extracted from each study. Additional data extracted from those clinical studies included patient assessment of pain (using a 0-100 $\mathrm{mm}$ visual analog scale), patient global assessment of disease (using a 0-100 mm visual analog scale), patient withdrawals, withdrawals due to adverse effects or lack of effect, and risk of serious adverse effects, serious infections, and deaths. Tofacitinib $5 \mathrm{mg}$ bid appears to have a favorable impact on patient outcomes related to efficacy and safety when compared with baseline values and with comparator disease-modifying antirheumatic drugs and placebo. Improvements were seen in the composite and individual measures of disease activity. Serious adverse effects, other adverse consequences, overall withdrawals, and withdrawals due to adverse effects and lack of efficacy are similar or more favorable for tofacitinib versus comparator disease-modifying antirheumatic drugs and placebo. At this point, tofacitinib appears to have an important role in the treatment of rheumatoid arthritis through improvement in these patient outcomes. However, it may require years of additional clinical studies and postmarketing surveillance to fully characterize the benefit-to-risk ratio of tofacitinib in a larger and diverse patient population.

Keywords: tofacitinib, rheumatoid arthritis, patient-reported outcomes, quality of life

\section{Introduction}

Rheumatoid arthritis is a chronic, progressive autoimmune disease of joints associated with inflammation and destruction of joints and systemic effects. ${ }^{1,2}$ The most recent rheumatoid arthritis treatment guidelines were developed by the American College of Rheumatology (ACR) in 2012, the European Union League Against Rheumatism in 2013, and Canada in 2012. ${ }^{3-5}$ Tofacitinib was approved as a second-line treatment for moderateto-severe rheumatoid arthritis in patients who have inadequate response or intolerance to methotrexate in the USA in 2012 at 5 mg bid. It was subsequently approved in Japan, Kuwait, United Arab Emirates, Argentina, and Canada at $5 \mathrm{mg}$ bid and in Russia and 
Switzerland at both 5 and $10 \mathrm{mg}$ bid. ${ }^{6}$ However, in 2013, the European Medicines Agency (EMA) did not approve tofacitinib after two reviews due to concerns related to the risks of serious infections and other severe adverse effects. ${ }^{7}$ Tofacitinib is now approved in 40 countries and Pfizer Laboratories (New York, USA) plans to resubmit to the EMA for approval later in $2015 .{ }^{8}$ The US Food and Drug Administration (FDA) approved tofacitinib with labeling that includes warnings on serious infections and malignancies. ${ }^{9}$ The warnings are similar to those seen in the labeling for biologic disease-modifying antirheumatic drugs (DMARDs) used in the treatment of rheumatoid arthritis. Tofacitinib does not appear in the ACR or Canadian guidelines but is mentioned in the European Union League Against Rheumatism guidelines. The clinical use and sale of tofacitinib continues to expand, particularly in the USA. ${ }^{10,11}$ The impact of tofacitinib on the clinical and laboratory measures of rheumatoid arthritis (ACR20, ACR50, ACR70, DAS28, etc) is well documented in reviews and metaanalyses, ${ }^{12-20}$ but these do not focus on the impact on outcomes from the patient's perspective and do not include the latest studies. Patient-reported outcomes data are provided in almost all published studies and may also be provided as additional details in subanalyses of original studies or supplementary data. Pharmacoeconomic analyses were not included in this review in order to focus specifically on patient-reported and patient-related outcomes documented in clinical studies. The objectives of this review are to collect and evaluate data related to the impact of tofacitinib on patient-reported outcomes (quality of life, functionality, pain, and global disease assessment), major adverse consequences, and withdrawals.

\section{Methods}

Clinical studies on tofacitinib in rheumatoid arthritis served as the primary source for the data collected in this review. The selection criteria also included studies or reports written in English, blinded and open-label studies, prospective and retrospective, containing the original publication of the data, and data provided on at least one of the patient-specific outcome measures noted as follows. The studies were identified through a number of methods, initially through PubMed searches using the following search terms: tofacitinib, CP-690550, and rheumatoid arthritis and limiting the search to clinical studies. The same terms were used in searching for articles in the following databases: Cochrane Library, EBSCO Medline Complete, International Pharmaceutical Abstracts, ScienceDirect, and Scopus. The reference lists in meta-analyses and review articles on tofacitinib were also searched for clinical studies.
Selection criteria for the studies included any studies that were prospective Phase II, Phase III, or other original studies evaluating efficacy and/or safety of tofacitinib in rheumatoid arthritis. The authors extracted specific data from each study and any supplementary documents provided and then tabulated data on one or more specific outcomes. Data were verified through review by at least one other author.

Each of the studies selected was searched for data within each of the following general categories measures: patientreported composite measures and specific measures of disease outcomes, withdrawals, and serious adverse effects or consequences. The patient-reported composite measures of disease outcomes evaluated in each study, based on recommendations from the ACR and other rheumatology societies and experts, included: Health Assessment Questionnaire (HAQ, HAQ-II, and HAQ-Disability Index [HAQ-DI]), Functional Assessment of Chronic Illness Therapy Fatigue Scale, Short Form 36-Item Health Survey, Short Form 36-Item Arthritis Specific Health Index, Patient Activity Scale, Patient Activity Scale II, Routine Assessment of Patient Index Data with 3 measures, Arthritis Impact Measurement Scale (AIMS, AIMS2), European Quality of Life Measure, Multidimensional Health Assessment Questionnaire, Modified Health Questionnaire, and Rheumatoid Arthritis Quality of Life. ${ }^{21-24}$ The patient-reported specific measures of disease activity included patient assessment of pain (using a 0-100 $\mathrm{mm}$ visual analog scale) and the patient global assessment of disease (using a $0-100 \mathrm{~mm}$ visual analog scale). Withdrawal data used in this review included total withdrawals, withdrawals due to lack of efficacy, and withdrawals due to adverse effects. The data on serious adverse effects or consequences included serious adverse effects, serious infections, cancers, and deaths that occurred during the studies. ${ }^{21-24}$

The data extracted included improvement from baseline in units measured and percent improvement from baseline for HAQ-DI, patient assessment of pain, patient global assessment of disease, and other measures. Therefore, these numbers are positive in value to demonstrate improvement rather than the negative values reported in the studies that reflect improvement in those measures. Frequency counts and the percent of those counts based on the size of the entering groups were provided for the other measures. Percentages and visual analog scale results were rounded off to whole numbers.

The recommended dose for tofacitinib in the USA is $5 \mathrm{mg}$ bid, ${ }^{9}$ but lower and higher dosages have been used in clinical studies, and approval in Russia and Switzerland includes both 5 and $10 \mathrm{mg}$ bid. ${ }^{6}$ In order to simplify the data tables, data from 
1 and $3 \mathrm{mg}$ bid dosage groups were combined, data from $10 \mathrm{bid}$ and $20 \mathrm{mg}$ once-daily dosage groups were combined, and data from 15 and $30 \mathrm{mg}$ bid dosage groups were combined. Data from the $5 \mathrm{mg}$ bid groups were listed separately.

\section{Results}

A total of 12 clinical studies reported in 14 articles were identified, met the selection criteria, and were used in this review (Table 1). ${ }^{25-44}$ Two reports, which included subanalyses of data from studies, were also included..$^{25,26,33,37}$ Recent reports that did not meet the selection criteria included a Phase I study, which was short in duration and lacked efficacy measures..$^{39}$ A report of pooled adverse effect data from 13 studies was not the original study reporting those data, but select data from that report was used in describing the risk factors for serious infections. ${ }^{40}$

Another report of pooled data from studies was used to provide data on the development of cancers in patients on tofacitinib. ${ }^{41}$ A total of eleven studies were double-blind and randomized and one study was an open-label long-term extension study. ${ }^{25,27-36,38}$ All studies were parallel in design and a few studies also included a sequential design for patients who started on placebo and were placed on tofacitinib after 3-6 months (Table 1). Tofacitinib was compared with placebo, methotrexate, and/or adalimumab as monotherapy in five double-blind studies. ${ }^{25,28,30,35,38}$ Tofacitinib was combined with methotrexate or other nonbiologic DMARDs in the other six double-blind studies, ${ }^{27,29,31-34}$ including one study that compared tofacitinib, adalimumab, and placebo in patients also receiving methotrexate..$^{31}$

\section{Patient-reported composite health assessment measures}

All 12 studies used the HAQ-DI as the primary patientreported composite health assessment measure and 3 studies used additional patient-reported composite measures (Table 2). A change from baseline of greater than 0.22 is widely considered to be the minimum clinically important difference. ${ }^{22,27,30}$ However, one study used the threshold of a change of greater than 0.3 in classifying those as being HAQ-DI responders. ${ }^{26}$ Across most dosage ranges studied, tofacitinib showed clinically or statistically significant changes in baseline HAQ-DI scores when compared with placebo or comparator drug (Table 2). Changes in the HAQ-DI score were dose dependent in the vast majority of the studies using multiple dosages showing a greater improvement in the higher dosages, with one exception. ${ }^{29}$ Tofacitinib $5 \mathrm{mg}$ bid, the currently approved and most commonly studied dosage, was associated with average changes in HAQ-DI ranging from 0.4 to 0.9 , all above the threshold of 0.22 for a clinical important improvement. Of the 12 studies reporting HAQ-DI findings, 9 showed a statistically significant change in HAQ-DI for tofacitinib $5 \mathrm{mg}$ bid compared with placebo or comparator drug.

Additional patient-reported composite health assessment measurement tools were used in four reports. The Functional Assessment of Chronic Illness Therapy-fatigue instrument demonstrated that tofacitinib 5 and $10 \mathrm{mg}$ bid were statistically superior to placebo. ${ }^{30,34}$ The Short Form 36-item survey instrument demonstrated statistically significant improvement in the physical component scale in all studies reporting this outcome, but only in two studies for the mental component scale when comparing tofacitinib $5 \mathrm{mg}$ bid monotherapy and combination therapy with placebo (Table 2). ${ }^{26,27,37,38}$ Some improvement was seen in the Medical Outcomes Study Sleep Scale, but it was not statistically significant. ${ }^{37}$

Measures of health status improved either clinically, statistically, or both, in all studies investigating tofacitinib $5 \mathrm{mg}$ bid against baseline, placebo, or comparator drug when studied as monotherapy or in combination with other agents. Studies, which ranged in length from 6 weeks to 60 months, showed benefits in health status early in treatment and continued through longer periods of time. Given the studies that have been conducted so far, tofacitinib shows definite improvement in patient's quality of life and functional domains.

\section{Patient's assessment of pain and patient's global assessment of disease}

Data on patient's assessment of pain and/or patient's global assessment of disease were available in seven clinical studies (Table 3). Improvements in pain and global assessments were similar within each group when comparing monotherapy with combination therapy studies, except for the tofacitinib low-dose groups (1-3 mg bid). Tofacitinib $5 \mathrm{mg}$ bid was associated with a $45 \%-54 \%$ improvement in patient's assessment of pain and a 44\%-60\% improvement in patient's global assessment of disease. The tofacitinib 1-3 mg bid dosage groups were associated with less to similar improvement $(23 \%-56 \%)$ and the tofacitinib $10-30 \mathrm{mg}$ bid dosage groups were associated with similar to slightly higher improvements (39\%-62\%) in pain and global assessment of disease. However, placebo was associated with less improvement, ranging from $15 \%$ to $29 \%$ improvement in patient's assessment of pain ratings and $23 \%-39 \%$ improvement in patient's global assessment of disease ratings. 
Table I Studies included in this review of patient outcomes associated with the use of tofacitinib in rheumatoid arthritis

\begin{tabular}{|c|c|c|c|}
\hline Design & $\begin{array}{l}\text { Tofacitinib dose } \\
\text { (no of patients) }\end{array}$ & $\begin{array}{l}\text { Comparator(s) } \\
\text { (no of patients) }\end{array}$ & $\begin{array}{l}\text { Duration and } \\
\text { reference }\end{array}$ \\
\hline \multicolumn{4}{|c|}{ Tofacitinib DMARD monotherapy studies } \\
\hline \multirow[t]{3}{*}{ Phase II, double-blind } & 5 mg bid $(6 \mathrm{l})$ & Placebo (65) & 6 weeks $^{25,26}$ \\
\hline & 15 mg bid (69) & & \\
\hline & 30 mg bid (69) & & \\
\hline \multirow[t]{5}{*}{ Phase II, double-blind } & I mg bid (54) & Placebo (59) & 24 weeks $^{26}$ \\
\hline & $3 \mathrm{mg}$ bid $(5 \mathrm{I})$ & Adalimumab (53) & \\
\hline & 5 mg bid (49) & & \\
\hline & $10 \mathrm{mg}$ bid $(6 \mathrm{I})$ & & \\
\hline & 15 mg bid (57) & & \\
\hline \multirow[t]{3}{*}{ Phase III, double-blind } & 5 mg bid (243) & & 6 months $^{30}$ \\
\hline & 10 mg bid (245) & & \\
\hline & Placebo then 5 or $10 \mathrm{mg}$ bid $(120)^{\mathrm{a}}$ & & \\
\hline \multirow[t]{2}{*}{ Phase III, double-blind } & $5 \mathrm{mg}$ bid (373) & Methotrexate (I86) & 24 months $^{35}$ \\
\hline & 10 mg bid (397) & & \\
\hline \multirow[t]{5}{*}{ Phase II, double-blind } & I mg bid (53) & Placebo (52) & 12 weeks $^{38}$ \\
\hline & $3 \mathrm{mg}$ bid $(53)$ & & \\
\hline & 5 mg bid (52) & & \\
\hline & $10 \mathrm{mg}$ bid $(53)$ & & \\
\hline & 15 mg bid (54) & & \\
\hline \multicolumn{4}{|c|}{ Tofacitinib plus methotrexate or other nonbiologic DMARD studies } \\
\hline \multirow[t]{5}{*}{ Phase II, double-blind } & Methotrexate plus: & Methotrexate plus: & 12 weeks $^{27}$ \\
\hline & I mg bid $(28)$ & Placebo $(28)$ & \\
\hline & $3 \mathrm{mg}$ bid $(28)$ & & \\
\hline & $5 \mathrm{mg}$ bid $(28)$ & & \\
\hline & $10 \mathrm{mg}$ bid $(28)$ & & \\
\hline \multirow[t]{7}{*}{ Phase II, double-blind } & Methotrexate plus: & Methotrexate plus: & 24 weeks $^{29}$ \\
\hline & I mg bid (7I) & Placebo (69) & \\
\hline & $3 \mathrm{mg}$ bid $(68)$ & & \\
\hline & $5 \mathrm{mg}$ bid $(7 \mathrm{I})$ & & \\
\hline & 10 mg bid (75) & & \\
\hline & 15 mg bid (75) & & \\
\hline & $20 \mathrm{mg}$ od $(80)$ & & \\
\hline \multirow[t]{5}{*}{ Phase III, double-blind } & Methotrexate plus: & Methotrexate plus: & 12 months $^{31}$ \\
\hline & $5 \mathrm{mg}$ bid $(204)$ & Placebo (69) & \\
\hline & $10 \mathrm{mg}$ bid $(20 \mathrm{I})$ & Adalimumab (204) & \\
\hline & Placebo then $5 \mathrm{mg}$ bid $(56)^{\mathrm{a}}$ & & \\
\hline & Placebo then $10 \mathrm{mg}$ bid $(52)^{\mathrm{a}}$ & & \\
\hline \multirow[t]{5}{*}{ Phase III, double-blind } & Methotrexate plus: & & 12 months $^{32}$ \\
\hline & $5 \mathrm{mg}$ bid $(32 \mathrm{I})$ & & \\
\hline & $10 \mathrm{mg}$ bid $(316)$ & & \\
\hline & Placebo then $5 \mathrm{mg}$ bid $(8 \mathrm{I})^{\mathrm{a}}$ & & \\
\hline & Placebo then $10 \mathrm{mg}$ bid $(79)^{\mathrm{a}}$ & & \\
\hline \multirow[t]{5}{*}{ Double-blind } & Nonbiologic DMARD plus: & & I year ${ }^{34}$ \\
\hline & $5 \mathrm{mg}$ bid $(3 \mid 8)$ & & \\
\hline & $10 \mathrm{mg}$ bid $(3 \mid 8)$ & & \\
\hline & Placebo then $5 \mathrm{mg}$ bid $(79)^{\mathrm{a}}$ & & \\
\hline & Placebo then $10 \mathrm{mg}$ bid $(80)^{\mathrm{a}}$ & & \\
\hline \multirow[t]{5}{*}{ Phase III, double-blind } & Methotrexate plus: & & 6 months $^{33,37}$ \\
\hline & $5 \mathrm{mg}$ bid $(133)$ & & \\
\hline & $10 \mathrm{mg}$ bid $(134)$ & & \\
\hline & Placebo then $5 \mathrm{mg}$ bid $(66)^{\mathrm{a}}$ & & \\
\hline & Placebo then $10 \mathrm{mg}$ bid $(66)^{\mathrm{a}}$ & & \\
\hline \multicolumn{4}{|c|}{ Tofacitinib monotherapy and combination DMARD study } \\
\hline \multirow[t]{2}{*}{ Open-label, long-term extension } & With/without nonbiologic DMARDs: & & 48 months $^{36}$ \\
\hline & $5-10 \mathrm{mg}$ bid $(4,102)$ & & \\
\hline
\end{tabular}

Note: ${ }^{a}$ On placebo for 3-6 months, then randomly assigned to tofacitinib at the dose indicated.

Abbreviations: bid, twice daily; DMARD, disease-modifying antirheumatic drug; QD, daily or once daily. 
Table 2 HAQ-DI and other composite measures

\begin{tabular}{|c|c|c|c|c|c|c|c|}
\hline \multirow[t]{3}{*}{ Outcome } & \multicolumn{6}{|c|}{ Improvement from baseline in units (\%) } & \multirow{3}{*}{$\begin{array}{l}\text { Duration and } \\
\text { reference }\end{array}$} \\
\hline & \multicolumn{4}{|l|}{ Tofacitinib } & \multirow[t]{2}{*}{ Placebo } & \multirow{2}{*}{$\begin{array}{l}\text { Comparator } \\
\text { DMARD }\end{array}$} & \\
\hline & I-3 mg bid & 5 mg bid & $\begin{array}{l}10 \mathrm{mg} \text { bid } \\
\text { or } 20 \mathrm{mg} \text { od }\end{array}$ & $\begin{array}{l}15-30 \mathrm{mg} \\
\text { bid }\end{array}$ & & & \\
\hline \multicolumn{8}{|c|}{ Tofacitinib DMARD monotherapy studies } \\
\hline HAQ-DI & & $0.6(35 \%)$ & & $0.7(44 \%)$ & $0.3(18 \%)$ & & 6 weeks $^{25}$ \\
\hline HAQ-DI & & $0.6 *$ & & $0.74 *(30 \mathrm{mg}$ bid $)$ & 0.2 & & 6 weeks $^{26}$ \\
\hline HAQ-DI & $0.25-0.44(16 \%-29 \%)$ & $0.51(36 \%)$ & $0.66(44 \%)$ & $0.82(51 \%)$ & $0.25(16 \%)$ & $\begin{array}{l}\text { Adalimumab } \\
0.35(24 \%)\end{array}$ & 24 weeks $^{28}$ \\
\hline HAQ-DI & & $0.50 *$ & $0.57^{*}$ & & 0.19 & & 6 months $^{30}$ \\
\hline HAQ-DI & & $0.9(60 \%)^{*}$ & $1.0(67 \%)^{*}$ & & & $\begin{array}{l}\text { Methotrexate } \\
0.7(47 \%)\end{array}$ & 24 months $^{35}$ \\
\hline HAQ-DI responders $\#$ & & $(57 \%)^{*}$ & & $(76 \%)^{*}$ & $(36 \%)$ & & 6 weeks $^{26}$ \\
\hline HAQ-DI responders ${ }^{\#}$ & & $(53 \%)^{*}$ & $(56 \%)$ & & $(32 \%)$ & & 6 months $^{30}$ \\
\hline HAQ-DI responders" & $(55 \%)^{*}$ & $(74 \%)^{*}$ & $(82 \%)^{*}$ & $(73 \%)^{*}$ & $(21 \%)$ & & 12 weeks $^{38}$ \\
\hline FACIT-Fatigue & & $6.7^{*}$ & $8.0 *$ & & 2.8 & & 6 months $^{30}$ \\
\hline FACIT-Fatigue & $2.5-5.4^{*}$ & $7.5^{*}$ & $8.5^{*}$ & $8.0^{*}$ & -1.4 & & 12 weeks $^{38}$ \\
\hline SF-36 PCS & & $8.3^{*}$ & & $9.9 *$ & 2.7 & & 6 weeks $^{26}$ \\
\hline SF-36 MCS & & 5.3 & & $9.81 *$ & 2.64 & & 6 weeks $^{26}$ \\
\hline SF-36 PCS responders $\$$ & $(62 \%)^{*}$ & $(82 \%)^{*}$ & $(86 \%)^{*}$ & $(83 \%)^{*}$ & $(25 \%)$ & & 12 weeks $^{38}$ \\
\hline SF-36 MCS responders $\$$ & $(45 \%)$ & $(74 \%)^{*}$ & $(66 \%)$ & $(56 \%)$ & $(27 \%)$ & & 12 weeks $^{38}$ \\
\hline \multicolumn{8}{|c|}{ Tofacitinib plus methotrexate or other nonbiologic DMARD studies } \\
\hline HAQ-DI & $0.38-0.41(32 \%-35 \%)^{\pi}$ & $0.49(4 \mid \%)^{*}$ & $0.57(48 \%)^{*}$ & & $0.05(4 \%)$ & & 12 weeks $^{27}$ \\
\hline HAQ-DI & $0.34-0.48(22 \%-35 \%) *$ & $0.49(34 \%)^{*}$ & $0.39-0.53$ & $0.43(30 \%)^{*}$ & $0.16(13 \%)$ & & 24 weeks $^{29}$ \\
\hline & & & $(29 \%-36 \%) *$ & & & & \\
\hline HAQ-DI & & $0.55(37 \%)^{*}$ & $0.6 \mathrm{I}(44 \%)^{*}$ & & $0.24(16 \%)$ & $\begin{array}{l}\text { Adalimumab } \\
0.49(33 \%)\end{array}$ & 12 months $^{31}$ \\
\hline HAQ-DI & & $0.40(28 \%)$ & $0.54(39 \%) *$ & & 0.15 (II\%) & & 12 months $^{32}$ \\
\hline HAQ-DI & & $0.44(31 \%)^{*}$ & $0.53(37 \%)^{*}$ & & $0.16(12 \%)$ & & I year ${ }^{34}$ \\
\hline HAQ-DI & & $0.43(27 \%)^{*}$ & $0.46(31 \%) *$ & & $0.18(11 \%)$ & & 6 months $^{33}$ \\
\hline HAQ-DI responders" & $(54 \%-63 \%)^{*}$ & $(79 \%)^{*}$ & $(81 \%)^{*}$ & & $(33 \%)$ & & 12 weeks $^{27}$ \\
\hline FACIT-Fatigue & & $5.8^{\wedge} * *$ & $6.8^{\wedge} *$ & & $2.0^{\wedge}$ & & I year ${ }^{34}$ \\
\hline FACIT-Fatigue & & $6.3^{*}$ & $4.6^{\wedge}, *$ & & I.I & & 6 months $^{37}$ \\
\hline SF-36 PCS & & $5.7(18 \%)^{*}$ & $6.6(20 \%)^{*}$ & & $2.0(7 \%)$ & & 6 months $^{37}$ \\
\hline SF-36 PCS responders $\$$ & $(75 \%)^{\pi}$ & $(79 \%)^{*}$ & $(76 \%)^{*}$ & & $(25 \%)$ & & 12 weeks $^{27}$ \\
\hline SF-36 PCS responders $\$$ & & $(68 \%)^{*}$ & $(66 \%)^{*}$ & & (49\%) & & 6 months $^{37}$ \\
\hline SF-36 MCS & & $3.5(8 \%)^{*}$ & $4.0(9 \%)^{*}$ & & $0.4(1 \%)$ & & 6 months $^{37}$ \\
\hline SF-36 MCS responders $\$$ & $(58 \%)^{\pi}$ & NR & NR & & $(29 \%)$ & & 12 weeks $^{27}$ \\
\hline SF-36 MCS responders $\$$ & & $(54 \%)^{*}$ & $(50 \%)^{*}$ & & $(37 \%)$ & & 6 months $^{37}$ \\
\hline MOS-SS & & $6.8(16 \%)$ & $5.8(14 \%)$ & & $3.8(8 \%)$ & & 6 months $^{37}$ \\
\hline \multicolumn{8}{|c|}{ Tofacitinib monotherapy and combination DMARD study } \\
\hline HAQ-DI & & $0.8(57 \%)$ & & & & & 60 months $^{36}$ \\
\hline
\end{tabular}

Notes: $* P<0.05$ for tofacitinib at this dose versus placebo or comparator; ${ }^{\top} P<0.05$ for tofacitinib at this dose versus placebo or comparator for only one of the two groups; \#HAQ-DI responders = improvement of $\geq 0.22$ or $\geq 0.30$ units on HAQ-DI; \$SF-36 MCS or PCS responders =improvement of $\geq 2.5$ units from baseline on SF-36 MCS or PCS; 'estimated from a graph presented in the published study.

Abbreviations: bid, twice daily; DMARD, disease-modifying antirheumatic drug; FACIT-Fatigue, Functional Assessment of Chronic Illness Therapy-fatigue instrument; HAQ-DI, Health Assessment Questionnaire-Disability Index; MOS-SS, Medical Outcomes Study Sleep Scale; SF-36, Short Form 36 -item survey instrument; SF-36 MCS, SF-36 Mental Component Scale; SF-36 PCS, SF-36 Physical Component Scale.

In monotherapy studies, methotrexate was associated with $47 \%$ improvements in patient's assessment of pain and global assessment of disease, which was comparable to tofacitinib $5 \mathrm{mg}$ bid. ${ }^{35}$ Adalimumab was associated with $30 \%-32 \%$ improvements in patient's assessment of pain and global assessment of disease, which are lower than those seen with tofacitinib $5 \mathrm{mg}$ bid. ${ }^{28}$ In summary, tofacitinib is associated with improvements in patient-reported assessment of pain and global assessment of disease.

\section{Total withdrawals and withdrawals due to lack of efficacy}

Total withdrawals and withdrawals due to lack of efficacy for tofacitinib, comparators, and placebo demonstrate possible trends across type of study (monotherapy vs combination therapy), tofacitinib dose, and duration of study (Table 4). Tofacitinib as monotherapy is associated with fewer total withdrawals (range 5\%-21\%) compared with tofacitinib as combination therapy with other DMARDs (range 14\%-25\%) 
Table 3 Patient-reported assessment of pain and global assessment of disease in tofacitinib studies

\begin{tabular}{|c|c|c|c|c|c|c|c|}
\hline \multirow[t]{3}{*}{ Outcome } & \multicolumn{6}{|c|}{ Improvement from baseline in units (\%) } & \multirow{3}{*}{$\begin{array}{l}\text { Duration and } \\
\text { reference }\end{array}$} \\
\hline & \multicolumn{4}{|l|}{ Tofacitinib } & \multirow[t]{2}{*}{ Placebo } & \multirow{2}{*}{$\begin{array}{l}\text { Comparator } \\
\text { DMARD }\end{array}$} & \\
\hline & $\mathrm{I}-3 \mathrm{mg}$ bid & 5 mg bid & $\begin{array}{l}10 \mathrm{mg} \text { bid } \\
\text { or } 20 \mathrm{mg} \text { od }\end{array}$ & 15-30 mg bid & & & \\
\hline \multicolumn{8}{|c|}{ Tofacitinib DMARD monotherapy studies } \\
\hline Pain $^{\mathrm{a}}$ & & $34(50 \%)$ & & $40-44(59 \%-66 \%)$ & $10(15 \%)$ & & 6 weeks $^{25}$ \\
\hline Pain $^{\mathrm{a}}$ & $14-18$ (23\%-29\%) & 31 (48\%) & $34(54 \%)$ & $36(56 \%)$ & $17(27 \%)$ & $\begin{array}{l}\text { Adalimumab } \\
21 \text { ( } 32 \%)\end{array}$ & 24 weeks $^{28}$ \\
\hline Pain $^{\mathrm{a}}$ & & $32(54 \%)$ & $35(58 \%)$ & & & $\begin{array}{l}\text { Methotrexate } \\
28(47 \%)\end{array}$ & 24 months $^{35}$ \\
\hline Patient global ${ }^{\mathrm{a}}$ & & $35(50 \%)$ & & $39-40(61 \%-62 \%)$ & $15(23 \%)$ & & 6 weeks $^{25}$ \\
\hline Patient global ${ }^{\mathrm{a}}$ & $16-19(26 \%-32 \%)$ & 31 (46\%) & $33(53 \%)$ & $36(57 \%)$ & $16(27 \%)$ & $\begin{array}{l}\text { Adalimumab } \\
19(30 \%)\end{array}$ & 24 weeks $^{28}$ \\
\hline Patient global ${ }^{a}$ & & $32(53 \%)$ & $35(58 \%)$ & & & $\begin{array}{l}\text { Methotrexate } \\
27(47 \%)\end{array}$ & 24 months $^{35}$ \\
\hline \multicolumn{8}{|c|}{ Tofacitinib plus methotrexate or other nonbiologic DMARD studies } \\
\hline Pain $^{\mathrm{a}}$ & $23-33$ & 31 & 38 & & 6 & & 12 weeks $^{27}$ \\
\hline Pain $^{\mathrm{a}}$ & $22-24(37 \%-44 \%)^{*}$ & $27(50 \%)^{*}$ & $22-26(39 \%-43 \%) *$ & $24(43 \%)^{*}$ & $13(25 \%)$ & & 24 weeks $^{29}$ \\
\hline Pain $^{\mathrm{a}}$ & & $27^{*}$ & $25^{*}$ & & 8 & & 6 months $^{33}$ \\
\hline Pain $^{\mathrm{a}}$ & & $26(45 \%) *$ & $30(52 \%) *$ & & $16(29 \%)$ & & 12 months $^{32}$ \\
\hline Patient global ${ }^{\mathrm{a}}$ & $27-38$ & 38 & 38 & & 7 & & 12 weeks $^{27}$ \\
\hline Patient global ${ }^{\mathrm{a}}$ & $28-32(44 \%-56 \%)^{*}$ & $34(60 \%)^{*}$ & $30-34(51 \%-56 \%)^{*}$ & 37 (6I\%)* & $23(39 \%)$ & & 24 weeks $^{29}$ \\
\hline Patient global ${ }^{\mathrm{a}}$ & & $26(44 \%)^{*}$ & $29(5 \mid \%)^{*}$ & & I 4 (25\%) & & 12 months $^{32}$ \\
\hline
\end{tabular}

Notes: $* P<0.05$ versus placebo or comparator; a patient assessment of pain and global assessment of disease on a 0-100 mm visual analog scale.

Abbreviations: bid, twice daily; DMARD, disease-modifying antirheumatic drug.

Table 4 Withdrawals in general and withdrawals due to lack of efficacy in tofacitinib studies

\begin{tabular}{|c|c|c|c|c|c|c|c|}
\hline \multirow[t]{3}{*}{ Event } & \multicolumn{6}{|c|}{ Number of events (\% of group) } & \multirow{3}{*}{$\begin{array}{l}\text { Duration and } \\
\text { reference }\end{array}$} \\
\hline & \multicolumn{4}{|l|}{ Tofacitinib } & \multirow[t]{2}{*}{ Placebo } & \multirow{2}{*}{$\begin{array}{l}\text { Comparator } \\
\text { DMARD }\end{array}$} & \\
\hline & I-3 mg bid & 5 mg bid & $\begin{array}{l}10 \mathrm{mg} \text { bid } \\
\text { or } 20 \mathrm{mg} \text { od }\end{array}$ & I5-30 mg bid & & & \\
\hline \multicolumn{8}{|c|}{ Tofacitinib DMARD monotherapy studies } \\
\hline Wd all & & $3(5 \%)$ & & $26(19 \%)$ & $17(26 \%)$ & & 6 weeks $^{25}$ \\
\hline Wd all & $22(21 \%)$ & $6(12 \%)$ & $6(10 \%)$ & $5(9 \%)$ & $16(27 \%)$ & $\begin{array}{l}\text { Adalimumab } \\
16(30 \%)\end{array}$ & 24 weeks $^{28}$ \\
\hline Wd all & $6(6 \%)$ & $2(4 \%)$ & $4(8 \%)$ & $2(4 \%)$ & $4(8 \%)$ & & 12 weeks $^{38}$ \\
\hline Wd inefficacy & & $\mathrm{I}(2 \%)$ & & $2(1 \%)$ & $8(12 \%)$ & & 6 weeks $^{25}$ \\
\hline Wd inefficacy & $6(6 \%)$ & $\mathrm{I}(2 \%)$ & $\mathrm{I}(2 \%)$ & 0 & $4(7 \%)$ & $\begin{array}{l}\text { Adalimumab } \\
5(9 \%)\end{array}$ & 24 weeks $^{28}$ \\
\hline Wd inefficacy & $2(2 \%)$ & 0 & 0 & 0 & $2(4 \%)$ & & 12 weeks $^{38}$ \\
\hline \multicolumn{8}{|c|}{ Tofacitinib plus methotrexate or other nonbiologic DMARD studies } \\
\hline Wd all & $7(13 \%)$ & $5(18 \%)$ & $7(25 \%)$ & & $5(18 \%)$ & & 12 weeks $^{27}$ \\
\hline Wd all & $20(14 \%)$ & $15(21 \%)$ & $22(14 \%)$ & $15(20 \%)$ & $15(22 \%)$ & & 24 weeks $^{29}$ \\
\hline Wd all & & $38(19 \%)$ & $44(23 \%)$ & & $6(5 \%)$ & & 6 months $^{33}$ \\
\hline Wd all & & $71(22 \%)$ & $51(16 \%)$ & & & & 12 months $^{32}$ \\
\hline Wd all & & $53(17 \%)$ & $64(20 \%)$ & & $13(8 \%)$ & & I year ${ }^{34}$ \\
\hline Wd inefficacy & $\mathrm{I}(2 \%)$ & 0 & 0 & & I (4\%) & & 12 weeks $^{27}$ \\
\hline Wd inefficacy & $2(1 \%)$ & $\mathrm{I}(1 \%)$ & $\mathrm{I}(\mathrm{l} \%)$ & 0 & $5(7 \%)$ & & 24 weeks $^{29}$ \\
\hline Wd inefficacy & & $5(3 \%)$ & $11(6 \%)$ & & $2(2 \%)$ & & 6 months $^{33}$ \\
\hline Wd inefficacy & & $7(2 \%)$ & $3(1 \%)$ & & & & 12 months $^{32}$ \\
\hline Wd inefficacy & & $16(4 \%)$ & $12(4 \%)$ & & & & I year ${ }^{34}$ \\
\hline \multicolumn{8}{|c|}{ Tofacitinib monotherapy and combination DMARD study } \\
\hline Wd all & & $852(21 \%)$ & & & & & 60 months $^{36}$ \\
\hline
\end{tabular}

Abbreviations: bid, twice daily; DMARD, disease-modifying antirheumatic drug; Wd, withdrawal. 
and adalimumab monotherapy (30\%) or placebo monotherapy $(26 \%-27 \%)$. However, there is no apparent consistent pattern of differences in total withdrawal rates in combination therapy studies comparing tofacitinib with placebo or among the different doses of tofacitinib in monotherapy and combination therapy studies (Table 4).

The withdrawal rates due to lack of efficacy are lower for tofacitinib monotherapy groups (range $0 \%-6 \%$ ) compared with adalimumab and placebo monotherapy groups (range 7\%-12\%). However, the withdrawal rates due to lack of efficacy were similar for tofacitinib monotherapy groups (range $0 \%-6 \%$ ), tofacitinib-DMARD combination groups (range $0 \%-6 \%$ ), and placebo-DMARD combination groups (2\%-7\%). Withdrawal due to lack of efficacy may be higher for tofacitinib 1-3 mg bid monotherapy groups $(6 \%)$ compared with tofacitinib at higher doses $(0 \%-2 \%)$ in one study, ${ }^{28}$ but not in the combination therapy studies.

In long-term extension studies, the rate of withdrawal secondary to all causes was reported to be $21 \%$ for tofacitinib $5 \mathrm{mg}$ bid or tofacitinib $10 \mathrm{mg}$ bid, with or without background DMARD therapy. ${ }^{36}$ Although those receiving efficacy is achieved and sustained over 48 months, the efficacy over time was likely influenced by the decreased persistence on tofacitinib therapy over time.

In summary, total withdrawals and withdrawals due to lack of efficacy for tofacitinib appear to be similar or fewer than withdrawals from placebo or other comparators.

\section{Withdrawal for adverse drug reactions}

During tofacitinib DMARD monotherapy studies, the percentage of withdrawals from tofacitinib secondary to adverse drug reactions ranged from $1 \%$ to $7 \%$ in studies lasting 6 weeks to 6 months and increased to a range of $10 \%-13 \%$ in a 24-month study (Table 5). ${ }^{35}$ Additionally, these percentages remained comparable between the 5 and the $10 \mathrm{mg}$ bid or $20 \mathrm{mg}$ od dose arms across the monotherapy studies. Studies of tofacitinib-DMARD combination from 12 weeks to 1 year demonstrated similar percent of withdrawal rates secondary to adverse events in the 5 and the $10 \mathrm{mg}$ bid or $20 \mathrm{mg}$ od dose arms, ranging from $1 \%$ to $14 \%$ (Table 5). There were no apparent consistent trends for withdrawal due to adverse effects when comparing tofacitinib with comparators or placebo (Table 5). Furthermore, discontinuations secondary to adverse effects in long-term extension studies occurred in $11 \%$ of patients and had an incidence rate of 7.3 events per 100 patient-years, with the most frequent types of adverse effects resulting in withdrawal due to laboratory study abnormalities, infestations and infections, and neoplasias. ${ }^{36}$ Additional reported adverse drug reactions leading to trial withdrawal consisted of neutropenia, leukopenia, myocardial ischemia, moderate bronchitis, lymphadenopathy, and pyelonephritis among others. ${ }^{25}$ In summary, withdrawals due to adverse effects increase with increased duration but are generally comparable across the different doses of tofacitinib and with placebo and other comparator DMARDs.

\section{Serious adverse drug reactions}

The percent of serious adverse events during tofacitinib DMARD monotherapy studies in the 5 and $10 \mathrm{mg}$ bid arms appeared to increase with study duration from $0 \%$ to $7 \%$ in 6-week to 6-month studies compared with 11\% in a 24-month study (Table 5). Tofacitinib DMARD monotherapy studies with durations of 6 and 24 weeks reported no cases of serious adverse drug reactions in the $5 \mathrm{mg}$ bid group, $2 \%$ occurrence in a 6-month study, and $11 \%$ occurrence in 24-month study. There was no apparent consistent pattern of increases in serious adverse drug reactions seen with higher doses compared with lower doses. In combination DMARD studies, tofacitinib was associated with similar occurrence of serious adverse drug events across all dosages of tofacitinib. In addition, long-term extension studies reported an incidence rate of 11.1 serious adverse events per 100 patient-years with $15 \%$ of patients experiencing serious adverse events. ${ }^{36}$ Similar to withdrawals due to adverse effects, the rates of serious adverse effects increased as study duration increased, but were generally comparable across the different doses of tofacitinib and with placebo and other comparator DMARDs.

\section{Serious infections}

The occurrence of serious infections in various studies ranged from $1 \%$ to $3 \%$ and was similar with respect to duration of therapy or intervention in both monotherapy and combination studies (Table 5). Incidence rates of 4.17 serious infections per 100 patient-years with tofacitinib $5 \mathrm{mg}$ bid, 2.32 per 100 patient-years with tofacitinib $10 \mathrm{mg}$ bid, and 3.68 per 100 patient-years with placebo were reported in a 1-year study. ${ }^{34}$ Comparatively, serious infections occurred in 184 patients (4\%) with an incidence rate of 3.1 events per 100 patientyears during long-term extension studies. ${ }^{36}$

An analysis of infections in all prior Phase II, Phase III, and long-term extension studies was not used in the initial data, but provides data on predictors of serious infections. ${ }^{40}$ The independent predictors associated with elevated risk for serious infections included: age $\geq 65$ years 
Table 5 Major safety events: serious adverse drug reactions, serious infections, cancers, deaths, and withdrawal due to lack of efficacy in tofacitinib studies

\begin{tabular}{|c|c|c|c|c|c|c|c|}
\hline \multirow[t]{3}{*}{ Event } & \multicolumn{6}{|c|}{ Number of events (\% of group) } & \multirow{3}{*}{$\begin{array}{l}\text { Duration anc } \\
\text { reference }\end{array}$} \\
\hline & \multicolumn{4}{|c|}{ Tofacitinib } & \multirow[t]{2}{*}{ Placebo } & \multirow{2}{*}{$\begin{array}{l}\text { Comparator } \\
\text { DMARD }\end{array}$} & \\
\hline & I-3 mg bid & 5 mg bid & $\begin{array}{l}10 \mathrm{mg} \text { bid } \\
\text { or } 20 \mathrm{mg} \text { od }\end{array}$ & I5-30 mg bid & & & \\
\hline \multicolumn{8}{|c|}{ Tofacitinib DMARD monotherapy studies } \\
\hline Wd ADR & & $\mathrm{I}(2 \%)$ & & $9(7 \%)$ & $\mathrm{I}(2 \%)$ & & 6 weeks $^{25}$ \\
\hline Wd ADR & $2(2 \%)$ & $\mathrm{I}(2 \%)$ & I (2\%) & $2(4 \%)$ & 0 & $\begin{array}{l}\text { Adalimumab } \\
3(6 \%)\end{array}$ & 24 weeks $^{28}$ \\
\hline Wd ADRs & & $3(1 \%)$ & II (4\%) & & $5(4 \%)$ & & 6 months $^{30}$ \\
\hline Wd ADRs & & $40(11 \%)$ & $4 \mathrm{I}(10 \%)$ & & & $\begin{array}{l}\text { Methotrexate } \\
25(13 \%)\end{array}$ & 24 months $^{35}$ \\
\hline Wd ADRs & $\mathrm{I}(\mathrm{I} \%)$ & $2(4 \%)$ & $3(6 \%)$ & 0 & $2(4 \%)$ & & 12 weeks $^{38}$ \\
\hline Serious ADRs & & 0 & & $2(1 \%)$ & $\mathrm{I}(2 \%)$ & & 6 weeks $^{25}$ \\
\hline Serious ADRs & $3(3 \%)$ & 0 & I (2\%) & $4(7 \%)$ & $2(3 \%)$ & $\begin{array}{l}\text { Adalimumab } \\
\text { I (2\%) }\end{array}$ & 24 weeks $^{28}$ \\
\hline Serious ADRs & & $6(2 \%)$ & II (4\%) & & 0 & & 6 months $^{30}$ \\
\hline Serious ADRs & & $40(11 \%)$ & 43 (1 I\%) & & & $\begin{array}{l}\text { Methotrexate } \\
22(12 \%)\end{array}$ & 24 months $^{35}$ \\
\hline Serious ADRs & $3(3 \%)$ & I (2\%) & I (2\%) & I (2\%) & 0 & & 12 weeks $^{38}$ \\
\hline Serious infections & & $\mathrm{I}(<1 \%)$ & $4(1 \%)$ & & $2(1 \%)$ & & 6 months $^{30}$ \\
\hline Serious infections & & II (3\%) & $8(2 \%)$ & & & $\begin{array}{l}\text { Methotrexate } \\
5(3 \%)\end{array}$ & 24 months $^{35}$ \\
\hline Serious infections & 0 & 0 & 0 & 0 & 0 & & 12 weeks $^{38}$ \\
\hline Cancers & & $2(1 \%)$ & $3(1 \%)$ & & & $\begin{array}{l}\text { Methotrexate } \\
\text { I (I\%) }\end{array}$ & 24 months $^{35}$ \\
\hline Deaths & & 0 & & 0 & 0 & & 6 weeks $^{25}$ \\
\hline Deaths & 0 & 0 & 0 & I $(2 \%)$ & 0 & $\begin{array}{l}\text { Adalimumab } \\
0\end{array}$ & 24 weeks $^{28}$ \\
\hline Deaths & & 0 & $\mathrm{I}(<\mathrm{I} \%)$ & & 0 & & 6 months $^{30}$ \\
\hline Deaths & & $3(1 \%)$ & $\mathrm{I}(<\mathrm{I} \%)$ & & & $\begin{array}{l}\text { Methotrexate } \\
0\end{array}$ & 24 months $^{35}$ \\
\hline \multicolumn{8}{|c|}{ Tofacitinib combination DMARD studies } \\
\hline Wd ADRs & $2(4 \%)$ & 4 (I4\%) & $4(14 \%)$ & & $2(7 \%)$ & & 12 weeks $^{27}$ \\
\hline Wd ADRs & $3(4 \%)$ & $5(4 \%)$ & I (I\%) & II (7\%) & 7 (9\%) & & 24 weeks $^{29}$ \\
\hline Wd ADRs & & $15(8 \%)$ & $15(8 \%)$ & & $2(2 \%)$ & & 6 months $^{33}$ \\
\hline Wd ADRs & & 14 (7\%) & $10(5 \%)$ & & $3(3 \%)$ & $\begin{array}{l}\text { Adalimumab } \\
19(5 \%)\end{array}$ & 12 months $^{31}$ \\
\hline Wd ADRs & & 36 (1 I\%) & $26(8 \%)$ & & & & 12 months $^{32}$ \\
\hline Wd ADRs & & $14(4 \%)$ & $20(6 \%)$ & & & & 12 months $s^{34}$ \\
\hline Serious ADRs & $2(4 \%)$ & I (4\%) & $2(8 \%)$ & & 0 & & 12 weeks $^{27}$ \\
\hline Serious ADRs & & $10(5 \%)$ & $10(5 \%)$ & & $6(5 \%)$ & & 6 months $^{33}$ \\
\hline Serious ADRs & & $12(6 \%)$ & $10(5 \%)$ & & $2(2 \%)$ & $\begin{array}{l}\text { Adalimumab } \\
2(3 \%)\end{array}$ & 12 months $^{31}$ \\
\hline Serious infections & I (I\%) & I (I\%) & $2(3 \%)$ & I (I\%) & 0 & & 24 weeks $^{29}$ \\
\hline Serious infections & & $3(2 \%)$ & $2(1 \%)$ & & 0 & & 6 months $^{33}$ \\
\hline Serious infections & & $3(1 \%)$ & $4(2 \%)$ & & I (I\%) & $\begin{array}{l}\text { Adalimumab } \\
0\end{array}$ & 12 months ${ }^{31}$ \\
\hline Deaths & 0 & 0 & 0 & & 0 & & 12 weeks $^{27}$ \\
\hline Deaths & $\mathrm{I}(\mathrm{I} \%)$ & 0 & 0 & 0 & 0 & & 24 weeks $^{27}$ \\
\hline Deaths & & 0 & $\mathrm{I}(1 \%)$ & & 0 & & 6 months $^{33}$ \\
\hline Deaths & & $\mathrm{I}(<1 \%)$ & 0 & & 0 & $\begin{array}{l}\text { Adalimumab } \\
I(<\mid \%)\end{array}$ & 12 months $^{31}$ \\
\hline Deaths & & $\mathrm{I}(<\mathrm{I} \%)$ & $\mathrm{I}(<\mathrm{I} \%)$ & & 0 & & 12 months $^{32}$ \\
\hline Deaths & & $4(1 \%)$ & $\mathrm{I}(<1 \%)$ & & $\mathrm{I}(\mathrm{l} \%)$ & & 12 months $^{34}$ \\
\hline \multicolumn{8}{|c|}{ Tofacitinib monotherapy and combination DMARD study } \\
\hline Wd ADRs & & 437 (11\%) & & & & & 60 months $^{36}$ \\
\hline Serious ADRs & & $630(15 \%)$ & & & & & 60 months $^{36}$ \\
\hline Serious infections & & $184(4 \%)$ & & & & & 60 months ${ }^{36}$ \\
\hline Cancers & & $107(2 \%)$ & & & & & $>42$ months $^{40}$ \\
\hline Cancers & & $60(1 \%)$ & & & & & 60 months $^{36}$ \\
\hline Deaths & & $31(1 \%)$ & & & & & 60 months $^{36}$ \\
\hline
\end{tabular}

Abbreviations: ADRs, adverse drug effects; bid, twice daily; DMARD, disease-modifying antirheumatic drug; Wd, withdrawal. 
(hazard ratio [HR]: 2.17; [95\% confidence interval (CI): 1.76-2.88]), diabetes (1.99 [1.39-2.85]), corticosteroid use of $\geq 7.5 \mathrm{mg}$ (1.4 [1.05-1.88]), and tofacitinib $10 \mathrm{mg}$ bid dose (1.4 [1.13-1.83]). ${ }^{40}$ In summary, the risk for serious infections is relatively low, is not associated with length of study or dose, and is similar to placebo and other comparators.

\section{Cancers}

The reported number of cases of cancer appeared to be low in these studies, ranging from $0 \%$ to $2 \%$, and did not appear to be related to the dose or duration of treatment (Table 5). A Phase III 24-month study reported six cases of confirmed cancer, five of which occurred in those on tofacitinib 5 and $10 \mathrm{mg}$ bid therapy, and one in a patient in the methotrexate group. ${ }^{35}$ The types of cancer reported included Burkitt's B-cell lymphoma, non-Hodgkin's lymphoma, colon cancer, chronic lymphocytic leukemia, prostate cancer, and gastric cancer. These cases represented $1 \%$ of participants from each group, which is comparable to the $1 \%$ of total participants with malignancies with an incidence rate of 1.0 events per 100 patient-years reported in the long-term extension studies. ${ }^{36}$ The number of cancers reported was small, so it is difficult to make conclusions other than to report the occurrence. A recent report that pooled data from prior studies, revealed 107 cancers in 5,671 patients (1.9\%) (Table 5). ${ }^{41}$ The development of cancers was similar to the expected rate in patients with moderate-to-severe rheumatoid arthritis and did not appear to increase as the duration of therapy increased. ${ }^{41}$

\section{Deaths}

The occurrence of death reported in tofacitinib studies appeared to be low and did not appear to be related to dose or study duration. The death rate ranged from $0 \%$ to $1 \%$ in monotherapy and combination studies of 6 weeks to 24 months duration (Table 5). A death rate of less than 1\% was reported during the long-term extension studies, with an incidence rate of 0.5 events per 100 patient-years. ${ }^{36}$ The number of deaths reported in these studies was also small, making it difficult to make conclusions.

\section{Discussion}

In addition to clinical and laboratory measures of disease activity, patient-reported and other patient-specific outcomes are also essential measures of effectiveness and safety in evaluating therapy in patients with rheumatoid arthritis. Patients' perception of pain and ability to perform daily activities are important measures of their satisfaction with the treatment of their disease, particularly in a chronic inflammatory disease such as rheumatoid arthritis. Adverse consequences from chronic therapies may lead to discontinuation of therapy or development of additional disease burden or death. This focused review of the impact of tofacitinib on these patient outcomes is needed to further understand and determine the appropriate use of tofacitinib in rheumatoid arthritis. This review also extends the number of studies covered in prior reviews and meta-analyses.

The major results of this review are that tofacitinib $5 \mathrm{mg}$ bid (the approved dosage in the USA) and other doses are associated with clinically and statistically significant improvements in the HAQ-DI and other patient-reported composite outcomes measures. These findings are similar to findings reported in prior meta-analyses, but this review includes all patient-centered outcomes mentioned in the studies reviewed and also includes data from more recent studies. ${ }^{14,16}$ Measurements of patient's pain and global assessment of disease demonstrated that tofacitinib $5 \mathrm{mg}$ bid was more effective than both placebo and tofacitinib 1-3 mg bid in both monotherapy and combination therapy studies.

Total withdrawals and withdrawals due to lack of efficacy appear to be fewer from the tofacitinib groups than those from placebo and comparator groups. These observations appear to be consistent with results from a meta-analysis, which reported that fewer subjects withdrew from the tofacitinib group than from the placebo group overall and due to lack of efficacy. ${ }^{17}$

Withdrawal rates due to adverse effects or lack of efficacy showed no apparent consistent pattern between dosage ranges, placebo, or comparator drug categories. The only noticeable trend was an increase in total withdrawal rates as the length of the study increased. This increase was also observed in placebo and comparator drug groups, but was not associated with tofacitinib dosage group. One monotherapy study reported a higher withdrawal rate due to lack of efficacy in the tofacitinib 1-3 mg bid group compared with tofacitinib $5 \mathrm{mg}$ bid and higher doses, but combination studies did not show this effect.

Our review indicates that withdrawals due to adverse effects are generally comparable across the tofacitinib dosage groups, placebo, and other comparator DMARD groups. This was reported in an earlier meta-analysis of tofacitinib, which found that although the rate of withdrawal due to adverse effects was higher in the tofacitinib group than the placebo group, the difference was not statistically significant. ${ }^{17}$ Therefore, more recent studies have not altered these overall findings regarding withdrawal due to adverse effects for tofacitinib, placebo, and comparator DMARDs. 
Incidences of serious adverse reactions were similar in all dosage groups, placebo, and comparator studies. Infection was a common adverse event leading to tofacitinib withdrawal. However, the risk of serious infections seems to be similar to placebo and other comparators and was not associated with study duration. Our observation includes more recent studies but is similar to that of a meta-analysis, which reported nonstatistical difference in incidences of infections between tofacitinib and placebo. ${ }^{12,14,16,17}$ The long-term extension study reported independent predictors associated with increased risk of serious infections, which included age $\geq 65$ years, presence of diabetes, corticosteroid use of $\geq 7.5 \mathrm{mg}$ od of prednisone (or equivalent), and tofacitinib $10 \mathrm{mg}$ bid. ${ }^{36}$ These predictors may help clinicians to determine which patients on tofacitinib to closely monitor for serious infections. Tofacitinib may decrease the response to some vaccines and therefore clinicians may consider administering vaccines prior to initiation of therapy with tofacitinib when possible to prevent the development of serious infections. ${ }^{42}$

The occurrence of cancer and death were low in this review and did not appear to be associated with study duration or study group (tofacitinib, placebo, or comparator DMARD). Cardiovascular disease is a major cause of death in patients with rheumatoid arthritis and that risk may be decreased or increased with DMARDs. ${ }^{43,44}$ However, further study is needed to determine the impact of tofacitinib on overall death rates and cardiovascular disease-associated deaths.

The limitations of this review are based on two major factors: the limitations of the duration and data provided in the available studies and the nature of the review. The data collected for this review were primarily from controlled clinical studies of 1 year or less in duration. Those data may or may not reflect the impact on patient outcomes during routine, long-term use of tofacitinib in rheumatoid arthritis. However, this is expected given the relatively short time since tofacitinib was approved. As more postmarketing data are collected, pharmacovigilance studies are needed to monitor the long-term safety and efficacy of this agent. The number of patient-reported composite measures was mostly limited to the HAQ-DI. This is a valid, reliable, and useful measure, but has its limitations in what is measured. Additional data on the impact of tofacitinib on the ability of patients to be productive in their personal and work life would be valuable additions. Many other patient outcome measures are available for use in future studies.

As noted above, the submissions for approval of tofacitinib were approved in the USA and numerous other countries, but not by the EMA following their initial and subsequent examinations in $2013 .{ }^{7}$ Specifically,

The CHMP [Committee for Medicinal Products for Human Use] had major concerns about the overall safety profile of Xeljanz. There were significant and unresolved concerns about the risk and type of serious infections seen with tofacitinib, which are related to the immunosuppressant action of the medicine. These safety concerns also included a risk of other severe side effects including certain cancers, gastro-intestinal perforations, (holes in the wall of the gut), liver damage and problems with increased lipid (fat) levels in the blood. It was not clear that these risks could be managed successfully in medical practice. ... However, the lack of robust evidence on prevention of structural damage with Xeljanz in the proposed dose and population still contributed to the Committee's view that the benefits of treatment did not outweigh significant and unresolved concerns about safety. ${ }^{7}$

The FDA approved tofacitinib, indicating the following on efficacy and concerns related to adverse effects:

In all of the trials, patients treated with Xeljanz experienced improvement in clinical response and physical functioning compared to patients treated with placebo. The use of Xeljanz was associated with an increased risk of serious infections, including opportunistic infections (infections that occur primarily when the immune system is suppressed), tuberculosis, cancers and lymphoma. Xeljanz carries a Boxed Warning regarding these safety risks. Xeljanz treatment is also associated with increases in cholesterol and liver enzyme tests and decreases in blood counts. The FDA approved Xeljanz with a Risk Evaluation and Mitigation Strategy (REMS), which consists of a Medication Guide advising patients about important safety information and a communication plan to inform health care providers about the serious risks associated with Xeljanz. To study the long-term effects of Xeljanz on heart disease, cancer, and serious infections, the FDA is requiring a postmarketing study that will evaluate two doses of Xeljanz and include a group of patients on another approved treatment to serve as a comparison. ${ }^{45}$

The effect of tofacitinib on cardiovascular events is complex. Cardiovascular events are increased in patients with rheumatoid arthritis, particularly in those with increased disease activity. A recent analysis has revealed that tumor necrosis factor inhibitors and methotrexate are associated with decreasing that risk. ${ }^{46}$ Both tofacitinib and tumor necrosis factor inhibitors decrease the inflammation in patients with 
rheumatoid arthritis. However, tofacitinib leads to an increase in total, low-density lipoprotein, and high-density lipoprotein cholesterol in patients, resulting in potential addition of lipid-lowering therapies. It is still too early to determine the effect of tofacitinib on the risk of cardiovascular events in patients with rheumatoid arthritis.

This review is limited by its nature as a review rather than being a prospective or retrospective study. It also lacks the statistical analyses associated with a meta-analysis. Additionally, this review included only published papers and may therefore be limited by publication bias of only those papers that have demonstrated a positive outcome. However, this review utilized strict criteria for study inclusion and data selection and provided data from all recent studies meeting those criteria.

\section{Conclusion}

Based on the evidence available and prior reviews and metaanalyses, ${ }^{12-20}$ tofacitinib $5 \mathrm{mg}$ bid appears to have a favorable impact on patient outcomes related to efficacy and safety, particularly when compared with placebo and comparator DMARDs. Increases in quality of life and functionality are significant and the overall discontinuation rate due to adverse effects and lack of efficacy are similar or better in some studies versus comparator DMARDs and placebo. Currently, tofacitinib appears to have an important role in the treatment of rheumatoid arthritis through improvement in these patient outcomes and a safety profile that is similar to comparator drugs in the studies presented to date. However, the approval by some countries but not others plus the requirements for risk evaluation and mitigation strategies and for postmarketing surveillance raise some concerns about the benefit-to-risk ratio of tofacitinib. Data from future clinical studies and postmarketing surveillance will clarify the benefit-to-risk ratio of tofacitinib in the treatment of rheumatoid arthritis.

\section{Disclosure}

The authors report no conflicts of interest in this work.

\section{References}

1. Aletaha D, Neogi T, Silman AJ, et al. 2010 Rheumatoid arthritis classification criteria: an American College of Rheumatology/European League Against Rheumatism collaborative initiative. Arthritis Rheum. 2010;62(9):2569-2581.

2. Scott DL, Wolfe F, Huizinga TWJ. Rheumatoid arthritis. Lancet. 2010; 376(9746):1094-1108.

3. Singh JA, Furst DE, Bharat A, et al. 2012 Update of the 2008 American College of Rheumatology recommendations for the use of disease-modifying antirheumatic drugs and biologic agents in the treatment of rheumatoid arthritis. Arthritis Care Res (Hoboken). 2012; 64(5):625-639.
4. Smolen JS, Landewé R, Breedveld, et al. EULAR recommendations for the management of rheumatoid arthritis with synthetic and biologic disease-modifying drugs: 2013 update. Ann Rheum Dis. 2014; 73(3):492-509.

5. Bykerk VP, Akhavan P, Hazlewood GS, et al. Canadian Rheumatology Association recommendations for pharmacological management of rheumatoid arthritis with traditional and biologic disease-modifying antirheumatic drugs. J Rheumatol. 2012;39(8):1559-1582.

6. Pfizer News and Media - Press Releases. Pfizer provides update on global regulatory approvals and launches of Xeljanz ${ }^{\mathbb{B}}$ (tofacitinib citrate) for the treatment of rheumatoid arthritis. 2013 [July 15]. Available from: http://www.pfizer.com/news/press-release/press-release-detail/pfizer_ provides_update_on_global_regulatory_approvals_and_launches_of_ xeljanz_tofacitinib_citrate_for_the_treatment_of_rheumatoid_arthritis. Accessed July 20, 2015.

7. European Medicines Agency - Find Medicine - Human Medicines Pending EC Decisions. Xeljanz. Available from: http://www. ema.europa.eu/ema/index.jsp?curl=pages/medicines/human/ medicines/002542/smops/Negative/human_smop_000501. jsp\&mid=WC0b01ac058001d127. Accessed July 20, 2015.

8. Pfizer - News and Media - Press Releases. Pfizer builds upon robust body of knowledge for XELJANZ ${ }^{\circledR}$ (tofacitinib citrate) with clinical trial and real-world use data at the European League Against Rheumatism Annual Congress (EULAR 2015). Available from: http://www. pfizer.com/news/press-release/press-release-detail/pfizer. Accessed October $15,2015$.

9. Xeljanz ${ }^{\circledR}$ (tofacitinib) film coated tablet [prescribing information] New York: Pfizer Labs; 2015.

10. Pfizer Financial Reports [homepage on the internet]. United States: 2014 Annual report to Shareholder: Financial report. Available from: http://www.pfizer.com/investors/financial_reports/financial_reports. Accessed July 7, 2015.

11. Pfizer Press Release [homepage on internet]. Pfizer reports first-quarter 2015 results. Available from: http:/www.pfizer.com/system/files/ presentation/Q1_2015_PFE_Earnings_Press_Release_foijsdflskd.pdf. Accessed July 7, 2015.

12. Song GG, Bae SC, Lee YH. Efficacy and safety of tofacitinib for active rheumatoid arthritis with an inadequate response to methotrexate or disease-modifying antirheumatic drugs: a meta-analysis of randomized controlled trials. Korean J Intern Med. 2014;29(5):656-663.

13. Ramiro S, Gaujoux-Viala C, Nam JL, et al. Safety of synthetic and biological DMARDs: a systematic literature review informing the 2013 update of the EULAR recommendations for management of rheumatoid arthritis. Ann Rheum Dis. 2014;73(3):529-535.

14. Zhang X, Liang F, Yin X, et al. Tofacitinib for acute rheumatoid arthritis patients who have had an inadequate response to disease-modifying antirheumatic drug (DMARD): a systematic review and meta-analysis. Clin Rheumatol. 2014;33(2):165-173.

15. Salgado E, Maneiro JR, Carmona L, Gomez-Reino JJ. Safety profile of protein kinase inhibitors in rheumatoid arthritis: systematic review and meta-analysis. Ann Rheum Dis. 2014;73(5):871-882.

16. Berhan A. Efficacy, safety and tolerability of tofacitinib in patients with an inadequate response to disease modifying anti-rheumatic drugs: a meta-analysis of randomized double-blind controlled studies. BMC Musculoskelet Disord. 2013;14:332.

17. He Y, Wong AY, Chan EW, et al. Efficacy and safety of tofacitinib in the treatment of rheumatoid arthritis: a systematic review and metaanalysis. BMC Musculoskelet Disord. 2013;14:298.

18. Kawalec P, Mikrut A, Wiśniewska N, Pilc A. The effectiveness of tofacitinib, a novel Janus kinase inhibitor, in the treatment of rheumatoid arthritis: a systematic review and meta-analysis. Clin Rheumatol. 2013;32(10):1415-1424.

19. Vyas D, O’Dell KM, Bandy JL, Boyce EG. Tofacitinib: The First Janus Kinase (JAK) inhibitor for the treatment of rheumatoid arthritis. Ann Pharmacother. 2013;47(11):1524-1531.

20. O'Dell KM, Rummel AE. Tofacitinib: a novel oral Janus kinase inhibitor for rheumatoid arthritis. Formulary. 2012;47(10):350-358. 
21. Anderson J, Caplan L, Yazdany J, et al. Rheumatoid arthritis disease activity measures: American College of Rheumatology recommendations for use in clinical practice. Arthritis Care Res (Hoboken). 2012; 64(5):660-667.

22. Maska L, Anderson J, Michaud K. Measures of functional status and quality of life in rheumatoid arthritis: Health Assessment Questionnaire Disability Index (HAQ), Modified Health Assessment Questionnaire (MHAQ), Multidimensional Health Assessment Questionnaire (MDHAQ), Health Assessment Questionnaire II (HAQ-II), Improved Health Assessment Questionnaire (Improved HAQ), and Rheumatoid Arthritis Quality of Life (RAQoL). Arthritis Care Res (Hoboken). 2011;63(Suppl 11):S4-S13.

23. Cella D, Yount S, Sorensen M, Chartash E, Sengupta N, Grober J. Validation of the Functional Assessment of Chronic Illness Therapy Fatigue Scale relative to other instrumentation in patients with rheumatoid arthritis. J Rheumatol. 2005;32(5):811-819.

24. Pincus T. The American College of Rheumatology (ACR) core data set and derivative "patient only" indices to assess rheumatoid arthritis. Clin Exp Rheumatol. 2005;23(5 Suppl 39):S109-S113.

25. Kremer JM, Bloom BJ, Breedveld FC, et al. The safety and efficacy of a JAK inhibitor in patients with active rheumatoid arthritis: results of a double-blind, placebo-controlled phase IIa trial of three dosage levels of CP-690,550 versus placebo. Arthritis Rheum. 2009;60(7):1895-1905.

26. Coombs JH, Bloom BJ, Breedveld FC, et al. Improved pain, physical functioning and health status in patients with rheumatoid arthritis treated with CP-690,550, an orally active Janus kinase (JAK) inhibitor: results from a randomised, double-blind, placebo-controlled trial. Ann Rheum Dis. 2010;69(2):413-416.

27. Tanaka Y, Suzuki M, Nakamura H, Toyoizumi S, Zwillich SH; Tofacitinib Study Investigators. Phase II study of tofacitinib (CP-690,550) combined with methotrexate in patients with rheumatoid arthritis and an inadequate response to methotrexate. Arthritis Care Res (Hoboken). 2011;63(8):1150-1158.

28. Fleischmann R, Cutolo M, Genovese MC, et al. A phase IIb doseranging study of the oral JAK inhibitor tofacitinib (CP-690,550) or adalimumab monotherapy versus placebo in patients with active rheumatoid arthritis with an inadequate response to disease-modifying antirheumatic drugs. Arthritis Rheum. 2012;64(3):617-629.

29. Kremer JM, Cohen S, Wilkinson BE, et al. A phase IIb dose-ranging study of the ORAL JAK inhibitor tofacitinib (CP-690,550) versus placebo in combination with background methotrexate in patients with active rheumatoid arthritis and an inadequate response to methotrexate alone. Arthritis Rheum. 2012;64(4):970-981.

30. Fleischmann R, Kremer J, Cush J, et al; ORAL Solo Investigators. Placebo-controlled trial of tofacitinib monotherapy in rheumatoid arthritis. N Engl J Med. 2012;367(6):495-507.

31. van Vollenhoven RF, Fleischmann R, Cohen S, et al; ORAL Standard Investigators. Tofacitinib or adalimumab versus placebo in rheumatoid arthritis. N Engl J Med. 2012;367(6):508-519.

32. Van der Heijde D, Tanaka Y, Fleischmann, et al; ORAL Scan Investigators. Tofacitinib (CP-690,550) in patients with rheumatoid arthritis receiving methotrexate: twelve-month data from a twenty-four-month phase III randomized radiographic study. Arthritis Rheum. 2013;65(3):559-570.

33. Burmester GR, Blanco R, Charles-Schoeman C, et al; ORAL Step Investigators. Tofacitinib (CP-690,550) in combination with methotrexate in patients with active rheumatoid arthritis with an inadequate response to tumour necrosis factor inhibitors: a randomized phase 3 trial. Lancet. 2013;381(9865):451-460.

Patient Related Outcome Measures

\section{Publish your work in this journal}

Patient Related Outcome Measures is an international, peer-reviewed, open access journal focusing on treatment outcomes specifically relevant to patients. All aspects of patient care are addressed within the journal and practitioners from all disciplines are invited to submit their work as well as healthcare researchers and patient support groups.
34. Kremer J, Li ZG, Hall S, et al. Tofacitinib in combination with nonbiologic disease-modifying antirheumatic drugs in patients with active rheumatoid arthritis: a randomized trial. Ann Intern Med. 2013; 159(4):253-261.

35. Lee EB, Fleischmann R, Hall S, et al; ORAL Start Investigators. Tofacitinib versus methotrexate in rheumatoid arthritis. $N$ Engl J Med. 2014;370(25):2377-2386

36. Wollenhaupt J, Silverfield J, Lee EB, et al. Safety and efficacy of tofacitinib, an oral Janus kinase inhibitor, for the treatment of rheumatoid arthritis in open-label, long-term extension studies. J Rheumatol. 2014; 41(5):837-852

37. Strand V, Burmester GR, Zerbini CAF, et al. Tofacitinib with methotrexate in third-line treatment of patients with active rheumatoid arthritis: patient-reported outcomes from a phase III trial. Arthritis Care Res (Hoboken). 2015:67(4):475-483.

38. Tanaka Y, Takeuchi T, Yamanaka H, Nakamura H, Toyoizumi S, Zwillich S. Efficacy and safety of tofacitinib as monotherapy in Japanese patients with active rheumatoid arthritis: a 12-week, randomized, phase 2 study. Mod Rheumatol. 2015;25(4):514-521.

39. Cohen S, Zwillich SH, Chow V, Labadie RR, Wilkinson B. Co-administration of the JAK inhibitor CP-690,550 and methotrexate is well tolerated in patients with rheumatoid arthritis without need for dose adjustment. Br J Clin Pharmacol. 2010;69(2):143-151.

40. Cohen S, Radominski SC, Gomez-Reino JJ, et al. Analysis of infections and all-cause mortality in phase II, phase III, and long-term extension studies of tofacitinib in patients with rheumatoid arthritis. Arthritis Rheumatol. 2014;66(11):2924-2937.

41. Curtis JR, Lee EB, Kaplan IV, et al. Tofacitinib, an oral Janus kinase inhibitor: analysis of malignancies across the rheumatoid arthritis clinical development programme. Ann Rheum Dis. Epub 2015 Apr 22.

42. Winthrop KL, Silverfield J, Racewicz A, et al. The effect of tofacitinib on pneumococcal and influenza vaccine responses in rheumatoid arthritis. Ann Rheum Dis. Epub 2015 Mar 20.

43. Solomon DH, Curtis JR, Saag KG, et al. Cardiovascular risk in rheumatoid arthritis: comparing TNF- $\alpha$ blockade with nonbiologic DMARDs. Am J Med. 2013:126(8):730.e9-730.e17.

44. Souto A, Salfado E, Maniero JR, Mera A, Carmona L, Gomez-Reino JJ. Lipid profile changes in patients with chronic inflammatory arthritis treated with biologic agents and tofacitinib in randomized clinical trials: a systematic review and meta-analysis. Arthritis Rheumatol. 2015:67(1):117-127.

45. US Food and Drug Administration - News and Events - FDA News Release. FDA approves Xeljanz for rheumatoid arthritis. Available from: http://www.fda.gov/NewsEvents/Newsroom/PressAnnouncements/ ucm327152.htm. Accessed October 15, 2015.

46. Roubille C, Richer V, Starnino T, et al. The effects of tumour necrosis factor inhibitors, methotrexate, non-steroidal anti-inflammatory drugs and corticosteroids on cardiovascular events in rheumatoid arthritis, psoriasis and psoriatic arthritis: a systematic review and meta-analysis. Ann Rheum Dis. 2015;74(3):480-489.
The manuscript management system is completely online and includes a very quick and fair peer-review system. Visit http://www.dovepress. com/testimonials.php to read real quotes from published authors. 